\title{
The Relationship between Children's Noncognitive Skills toward Food and Their Food Habits in a Cross-Sectional Study
}

\author{
Tomoko Osera $^{1,2}$, Setsuko Tsutie ${ }^{3}$, Misako Kobayashi ${ }^{2} \&$ Nobutaka Kurihara $^{1}$ \\ ${ }^{1}$ Hygiene and Preventive Medicine, Graduate School of Life Science, Kobe Women's University, Japan \\ ${ }^{2}$ Takakuradai Kindergarten attached to Kobe Women's University, Japan \\ ${ }^{3}$ Clinical Nutrition Management, Graduate School of Life Science, Kobe Women's University, Japan \\ Correspondence: Nobutaka Kurihara, Graduate School of Life Science, Kobe Women's University, 2-1 \\ Higashisuma-Aoyama, Suma, Kobe, Japan. Tel: 81-78-737-2417. E-mail: kurihara@ suma.kobe-wu.ac.jp
}

Received: November 24, 2017

Accepted: December 15, 2017 Online Published: January 15, 2018

doi:10.5539/jfr.v7n2p1

URL: https://doi.org/10.5539/jfr.v7n2p1

\begin{abstract}
Our previous study suggested that children's food preferences were related to their concern about food and respect for food. In general, concern and respect were sorts of non-cognitive skills, which are useful for future life if acquired during childhood. The aim of this study was to make clear how concern about food and respect for food were related to their food habits and life style. We investigated the relationship between children's non-cognitive skills and their food habits in a cross-sectional study. From 2007 to 2016, 2,408 Japanese kindergarten children aged 3 to 5 years were included in the study. The distribution was categorized into two patterns of their non-cognitive skills based on whether a particular the guardians answered children's non-cognitive skills, concern about food and respect for food. The high and low of non-cognitive skills toward food were related to lifestyle, food preferences and food habits. High non-cognitive skills toward food may be associated with to take good food habits and their preferences in kindergarten children.
\end{abstract}

Keywords: respect for food, concern about food, kindergarten children

\section{Introduction}

Non-cognitive skills during childhood are useful for future life. Non-cognitive skills have been broadly defined as representing the "patterns of thought, feelings and behavior" (Les et al, 2008). In general, concern and respect included in non-cognitive skill. Our previous study suggested that children's food preferences were related with their concern about food and respect for food (Osera et al, 2016a).

Childhood is a crucial period for developing food acceptance patterns (Cashdan, 1998). For example, children are exposed to unhealthy food choices, which may have contributed to the increase in the prevalence of overweight observed among youth in the past several years (St-onge, 2003). Less dislike for certain foods in high school students was related to good food habits at the present day as well as a lower numbers of disliked food items in childhood (Osera, 2017a). The development and long-term health of children are linked to food habits established from early childhood (Scaglioni, 2008). The aim of this study was to make clear how concern about food and respect for food were related to their food habits and lifestyle.

Non-cognitive skills have been studied by some economists and pedagogs. Hickman et al. (2006) showed that both cognitive and non-cognitive abilities determine social and economic success. Our demonstration that non-cognitive skills are important in explaining a diverse array of behaviours helps to explain why early childhood programs, such as Head Start and the Perry Preschool Program, are effective (Heckman, 2006). The Perry Preschool research study showed that high-quality preschool programs for young children living in poverty contributed to their intellectual and social development in childhood and their success in school and economic performance, and reduced incidence of crime in adulthood (Schweinhart, 2005). Therefore, non-cognitive skills during childhood are very important for future life (Duffy, 2000). During childhood is important to take high non-cognitive skills. In the study, we would like to demonstrate the relationship between non-cognitive skills toward food and their food habits and life style.

We investigated the relationship between children's "concern about food" and "respect for food" and their food habits and lifestyle in a cross-sectional study. 


\section{Method}

\subsection{Study Design and Subjects}

A study was using data from children in one kindergarten obtained over one decade, we conducted a study to determine whether or not the children's health was changed. From 2007 to 2016, 2,408 children aged 3 to 5 years from a kindergarten in Japan were included in the study. The questionnaire was distribution by every April in each year. The distribution was every children but the response rate was 98.0 \pm 3.1 during 10 years (Table 1). After we summed up all the data in cross-sectional study, we cleared no changes during one decade. These data were secondary usage.

Table 1. The response rate of the each study

\begin{tabular}{ccccccccccc}
\hline Year & 2007 & 2008 & 2009 & 2010 & 2011 & 2012 & 2013 & 2014 & 2015 & 2016 \\
\hline Response rate(\%) & 98.8 & 100.0 & 99.6 & 99.2 & 99.6 & 97.2 & 97.7 & 97.6 & 100.0 & 89.7 \\
\hline
\end{tabular}

\subsection{Questionnaire}

The main outcomes were height, weight, "respect for food", "concern about food" and food preferences. Because our previous study suggested that "respect for food" and "concern about food" were very important item for children's lifestyle (Osera, 2016a), we adopted these items. Therefore, we examined the relationship between the two non-cognitive skills (concern about food and respect for food) and 11 items. Of the 11 items, 2 lifestyle habits (waking time and sleeping time) and 9 behaviour related to food habits (help set the table, help with cooking, go shopping at the supermarket with parents, frequency of eating breakfast, talk about food while eating, talk about taste while eating, enjoy school lunch, food preference and number of foods preferred. Waking time and sleeping time were scored on a four-point scale, with higher scores indicating better habits. All other questions were scored on a five-point scale, with higher scores indicating better habits, except for food preference. Food preference was scored on a two-point scale, indicating presence or absence. 'Presence' means that the child disliked more than one food; 'absence' means that the child disliked no food. The guardians answered children's non-cognitive skills, concern about food and respect for food. In addition, all outcomes were self-reported by parents.

If a child disliked a food, we asked what kind of food from a list of 55 foods. These foods were all available in regular school lunches and were often disliked by children, as shown in our previous study (Osera, 2016a).

\subsection{Definitions of Overweight and Obesity}

For children, overweight and obesity were defined based on the Kaup score. Kaup score is use to define children's health, especially to check tendency of thin or obese in Japan. Overweight was defined as a kaup score of 16.5 to 18.5 , and obesity was defined as a kaup score of 18.5 or higher (Imamura, 1983).

\subsection{Statistical Analysis}

Differences in rates of mother's working style between years were examined using Fisher's exact probability test. Three-way analysis of variance (ANOVA) was used to change each item (e.g. height, weight) between age, sex and during one decade. $\mathrm{P}$ values $<0.05$ were considered to indicate statistical significance.

The distribution was categorised into two patterns of children's non-cognitive skills based on whether a particular the guardians answered children's non-cognitive skills, concern about food and respect for food. "Concern about food" was related with weight and healthy food habits in adolescents (MacFarlane et al, 2010). In the study non-cognitive skills toward food are defined as "concern about food" plus "respect for food." To address this definition, the maximum total score for concern about food and respect for food was 10 , the minimum was 1 and the mean and standard deviation were 7.6 \pm 1.6 . So, we distributed two groups. According to this procedure compared with high and low of two non-cognitive skills toward food of respect for food and concern about food. Three-way ANOVA was used to change each item (e.g. waking time, sleeping time, et al.) between age, sex and level of non-cognitive skill. $\mathrm{P}$ values $<0.05$ were considered to indicate statistical significance. The data were analyzed using SPSS for Windows, Version 23 (IBM, New York, NY. USA).

\subsection{Ethical Approval}

Guardians were informed about the objects and methods of this study and guardians answered the questionnaire only if they desired, in the absence of any compelling force and with the right of free withdrawal. Individual privacy was strictly protected thorough the investigation. Each study was approved by the president of the kindergarten. All guardians provided informed consent for participation in the each study. Under these conditions, 
the mothers agreed to cooperate in the scientific investigations in the kindergarten, including this study, when their children entered. The present study is based on the data which some studies with all participantes' permission. This work is a part of the study which has been approved by the Kobe Women's University Ethics Committee Regarding Human Subjects; H29-2.

\section{Results}

\subsection{Participant Characteristics}

Table 2 shows the age and sex distribution of each study sample. Differences in rates of mother's working style between years were examined using Fisher's exact probability test (Table 3). The proportion of mothers who were housewives was significantly lower in 2016 than in 2012 (75.3\% vs. 81.6\%; P $<0.001$, Fisher's exact probability test). The rate of obesity was $0.3 \%$, and the rate of overweight was $2.2 \%$ in the average of all data (data not shown).

Table 2. Distribution of the study samples by age, sex and survey year

\begin{tabular}{lcccccccccc}
\hline Year & 2007 & 2008 & 2009 & 2010 & 2011 & 2012 & 2013 & 2014 & 2015 & 2016 \\
\hline Boy & & & & & & & & & & \\
\hline Three years old & 31 & 19 & 40 & 30 & 28 & 47 & 28 & 28 & 21 & 23 \\
Four years old & 44 & 48 & 33 & 53 & 37 & 32 & 60 & 34 & 28 & 18 \\
Five years old & 50 & 46 & 48 & 34 & 54 & 36 & 33 & 58 & 35 & 29 \\
\hline Girl & & & & & & & & & & \\
\hline Three years old & 27 & 25 & 31 & 27 & 26 & 36 & 35 & 33 & 34 & 30 \\
Four years old & 44 & 63 & 42 & 56 & 49 & 51 & 55 & 40 & 39 & 37 \\
Five years old & 54 & 44 & 63 & 43 & 53 & 50 & 51 & 55 & 41 & 38 \\
\hline
\end{tabular}

$\mathrm{N}=$ number

Table 3. Differences between mother's working style and year

\begin{tabular}{lllllll}
\hline Year & 2012 & 2013 & 2014 & 2015 & 2016 & P value \\
\hline House wife & 81.6 & 76.3 & 74.9 & 76.0 & 75.3 & $<0.001$ \\
\hline
\end{tabular}

Note. Fisher's exact probability test: * $\mathrm{P}<0.05$, ** $\mathrm{P}<0.01$, *** $\mathrm{P}<0.001$

The ratio was Mother's housewives. The data before 2012 are not available, because we examined this question from 2012 .

\subsection{Relationship between Five Items (Height, Weight, Food Preferences, Concern about Food and Respect for Food) and Age and Sex During 10 Years}

Figure 1 shows the mean height according to age, sex and survey year. There were significant differences by age and sex, but there were no significant differences by year (age, $\mathrm{P}<0.001$; sex, $\mathrm{P}<0.001$; year, N.S.; three-way ANOVA) (Figure 1).

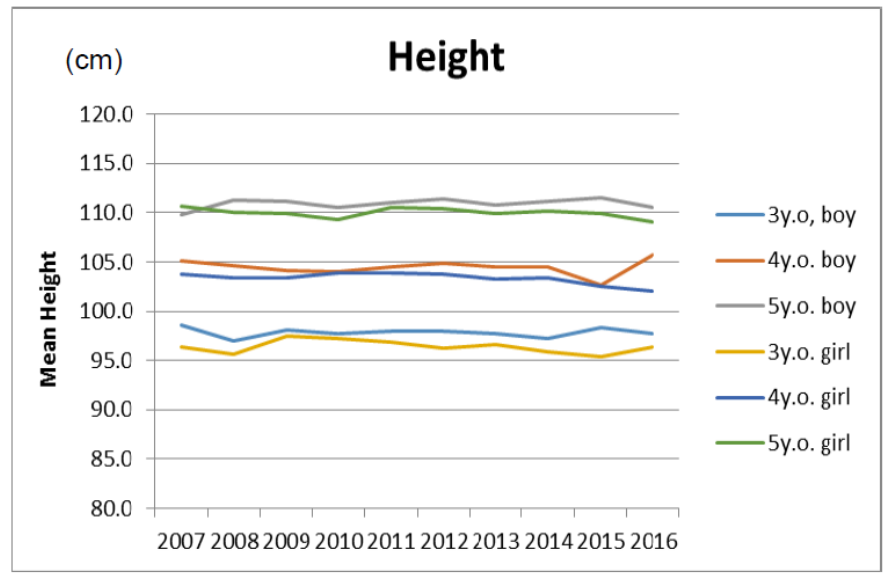

Figure 1. Height of study subjects by sex, age and survey year in the study population, 2007-2016

Note. Mean hight during one decade in terms of gender, age were assessed using Three way ANOVA; $* \mathrm{P}<0.05, * * \mathrm{P}<0.01, * * * \mathrm{P}<0.001$. Significant differences, age $* * * \mathrm{P}<0.001, \operatorname{sex} * * * \mathrm{P}<0.001$, year N.S. 


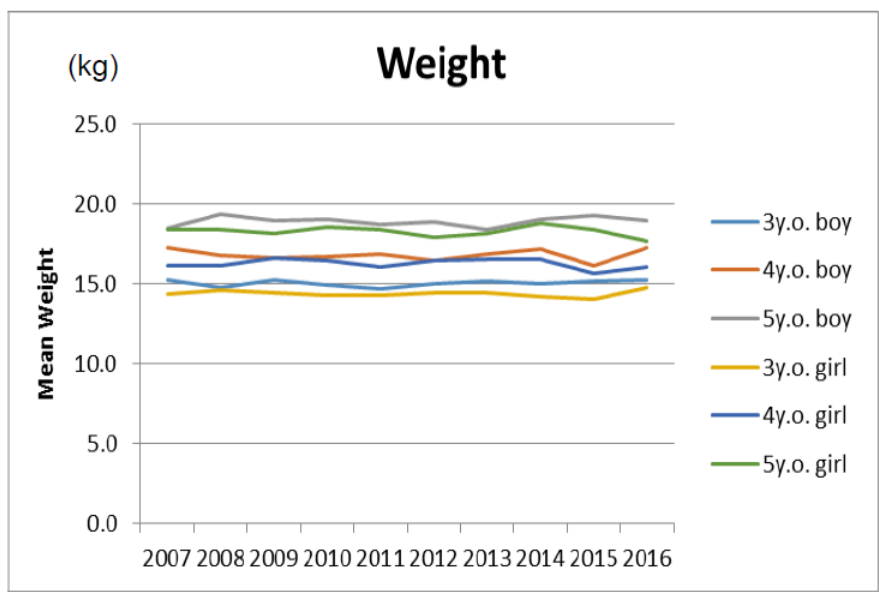

Figure 2. Weight of study subjects by sex, age and survey year in the study population, 2007-2016

Note. Mean weight during one decade in terms of gender, age were assessed using Three way ANOVA; $* \mathrm{P}<0.05, * * \mathrm{P}<0.01, * * * \mathrm{P}<$ 0.001. Significant differences, age $* * * \mathrm{P}<0.001$, sex $* * * \mathrm{P}<0.001$, year N.S.

The results for weight showed almost the same tendency as those for height. Figure 2 shows the mean weight according to age, sex and survey year. There were significant differences by age and sex, but there were no significant differences by year (age, $\mathrm{P}<0.001$; sex, $\mathrm{P}<0.001$; year, N.S.; three-way ANOVA) (Figure 2).

Figure 3 shows the mean food preference scores according to age, sex and survey year. There were no significant differences by age, sex or year (age, NS; sex, NS; year, NS; three-way ANOVA) (Figure 3).

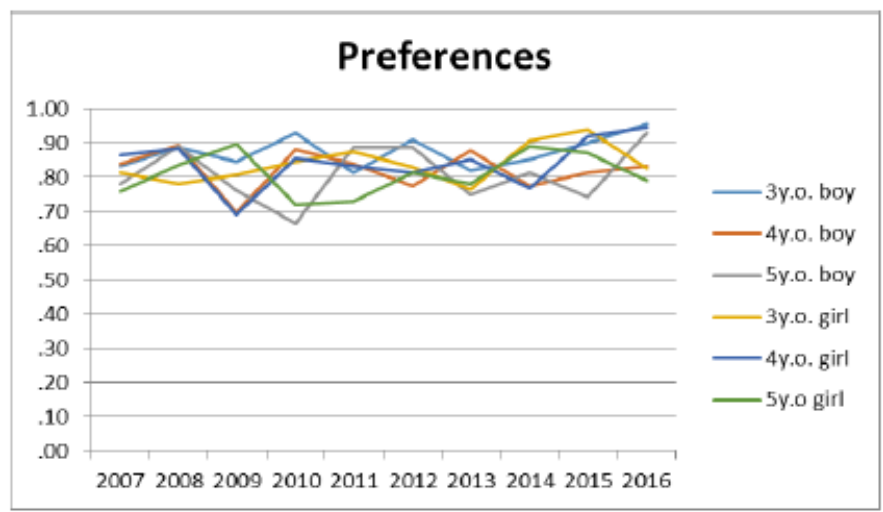

Figure 3. Preferences of study subjects by sex, age and survey year in the study population, 2007-2016.

Note. Children's food preferences during one decade in terms of gender, age were assessed using Three way ANOVA; $* \mathrm{P}<0.05, * * \mathrm{P}<0.01$, *** $\mathrm{P}<0.001$. Significant differences, age N.S., sex N.S., year N.S. Two point scale up to 0 to 1.1 was presence and 0 was absence.

Figure 4 shows the mean scores for concern about food according to age, sex and survey year. There were significant differences by age, sex and year (age, $\mathrm{P}<0.05$; sex, $\mathrm{P}<0.01$; year, $\mathrm{P}<0.05$; three-way ANOVA) (Figure 4). The results for respect for food showed almost the same tendency as those for concern about food.

Figure 5 shows the mean scores for results for respect for food according to age, sex and survey year. There were significant differences by age and sex, but there were no significant differences by year (age, $\mathrm{P}<0.001$; sex, $\mathrm{P}<$ 0.05; year, N.S.; three-way ANOVA) (Figure 5). 


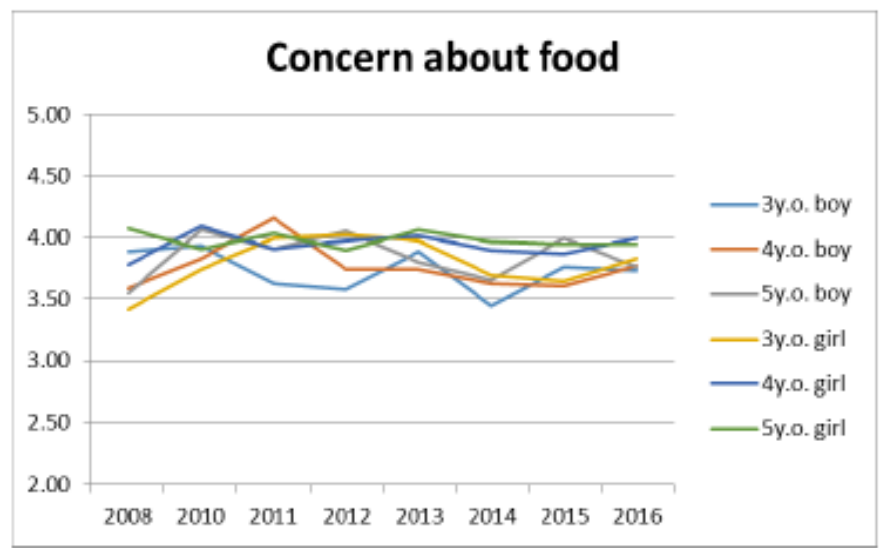

Figure 4. "Concern about food" of study subjects by sex, age and survey year in the study population, 2008-2016

Note. Mean "concern about food" during one decade in terms of gender, age were assessed using Three way ANOVA; * $\mathrm{P}<0.05, * * \mathrm{P}<0.01$, *** $\mathrm{P}<0.001$. Significant differences, age $* \mathrm{P}<0.05$, sex ** $\mathrm{P}<0.01$, year $* \mathrm{P}<0.05$ Five point scale up to 1 to 5 .

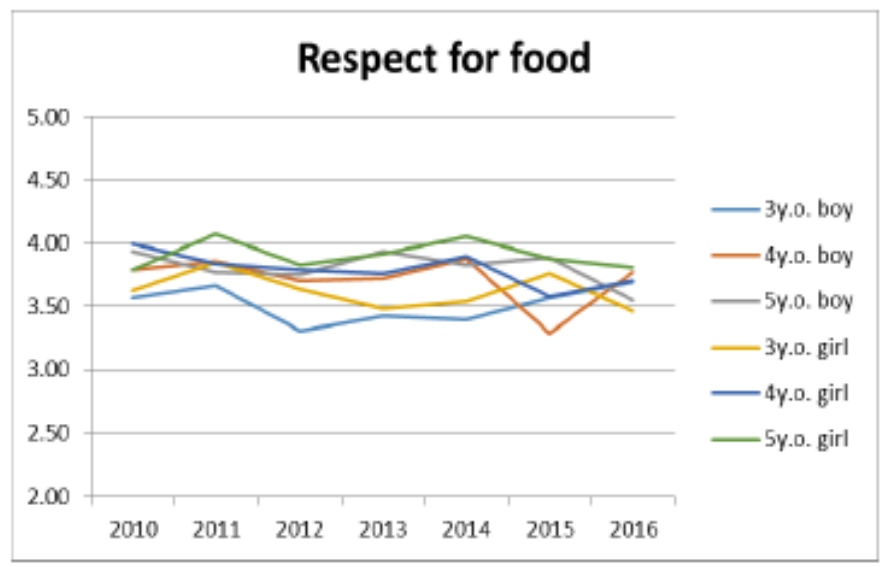

Figure 5. "Respect for food" of study subjects by sex, age and survey year in the study population, 2010-2016

Note. Mean "respect for food" during one decade in terms of gender, age were assessed using three way ANOVA; $* \mathrm{P}<0.05, * * \mathrm{P}<0.01$, $* * * \mathrm{P}<0.001$. Significant differences, age $* * * \mathrm{P}<0.001$, sex $* \mathrm{P}<0.05$, year N.S. Five point scale up to 1 to 5 .

\subsection{Noncognitive Skills toward Food Related With Life Style and Food Habits}

Table 4 shows the results for waking time and sleeping time. There were significant differences in non-cognitive skills toward food compared with high and low but there were no significant differences by age and sex. Frequency of eating breakfast, talking about food, talking about taste and food preferences showed the same tendency. There were significant differences in non-cognitive skills toward food compared with high and low but there were no significant differences by age and sex (Table 4).

Helping set the table, cooking and shopping were significant differences in non-cognitive skills toward food, age and sex (Table 4 and supplemental data, the data was not shown in the manuscript).

Enjoying school lunch and number of food preferences were significant differences non-cognitive skills and age but there were no significant differences by sex (Table 4). The score for enjoying school lunch increased with age from $4.1 \pm 0.9$ at 3 years, to $4.3 \pm 0.8$ at 4 years, to $4.4 \pm 0.9$ at 5 years (mean \pm SD). The score for number of food preferences decreased with age from $9.0 \pm 7.9$ at 3 years, to $6.6 \pm 6.1$ at 4 years, to $5.0 \pm 4.6$ at 5 years (mean $\pm \mathrm{SD}$, data not shown). 
Table 4. Relationship between high and low noncognitive skills toward food and their food habits

\begin{tabular}{|c|c|c|c|c|c|c|c|c|c|c|c|}
\hline & High & & & & Low & & & & $P$ value & & \\
\hline & & & & $\mathrm{N}$ & & & & $\mathrm{N}$ & skill & sex & age* \\
\hline Waking time $^{+}$ & 3.3 & \pm & 0.6 & 762 & 3.2 & \pm & 0.7 & 597 & $<0.001$ & N.S. & N.S. \\
\hline Sleeping time ${ }^{+}$ & 2.5 & \pm & 0.7 & 757 & 2.3 & \pm & 0.7 & 587 & $<0.001$ & N.S. & N.S. \\
\hline Help set the table ${ }^{++}$ & 4.1 & \pm & 0.8 & 329 & 3.7 & \pm & 1.0 & 288 & $<0.001$ & $<0.01$ & $<0.001$ \\
\hline Cooking & 3.7 & \pm & 1.0 & 910 & 3.4 & \pm & 1.1 & 691 & $<0.001$ & $<0.001$ & $<0.001$ \\
\hline Shopping $^{\$}$ & 4.4 & \pm & 0.8 & 707 & 4.2 & \pm & 1.0 & 521 & $<0.001$ & $<0.001$ & $<0.001$ \\
\hline Enjoying school lunch & 4.6 & \pm & 0.7 & 757 & 3.9 & \pm & 0.9 & 595 & $<0.001$ & N.S. & $<0.001$ \\
\hline Eat breakfast & 4.0 & \pm & 0.1 & 909 & 4.0 & \pm & 0.3 & 691 & $<0.01$ & N.S. & N.S. \\
\hline Talk about food & 4.2 & \pm & 0.7 & 761 & 3.8 & \pm & 0.8 & 596 & $<0.001$ & N.S. & N.S. \\
\hline Talk about taste & 4.3 & \pm & 0.7 & 480 & 3.9 & \pm & 0.8 & 376 & $<0.001$ & N.S. & N.S. \\
\hline Food preference ${ }^{+++}$ & 0.8 & \pm & 0.4 & 893 & 0.9 & \pm & 0.3 & 675 & $<0.001$ & N.S. & N.S. \\
\hline $\begin{array}{l}\text { Number of } \\
\text { food preferences }\end{array}$ & 4.9 & \pm & 4.6 & 370 & 8.9 & \pm & 7.8 & 338 & $<0.001$ & N.S. & $<0.001$ \\
\hline
\end{tabular}

Note. The relationship between non-cognitive skills toward food, age and sex were assessed using three way ANOVA; $* \mathrm{p}<0.05, * * \mathrm{p}<0.01$, $* * * \mathrm{p}<0.001$; The maximum total score for concern about food and respect for food was 10 , the minimum was 1 and the mean and standard deviation were 7.6 \pm 1.6 . Based on this, we devided into two groups. According to this procedure compared between high and low of two non-cognitive skills toward food, respect for food and concern about food. The data showed including all age children.* Mean of each age data was not shown. + Up to 4 point scale. Good habits indicate 4 point. ++ Up to 5 point scale. Good habits indicate 5 point. +++'Presence' means that students dislike more than one foods, 'Absence' means that students disliked no food. 1 was 'presence' and 0 was 'absence'. ++++ The foods student disliked, which were chosen themselves from a list of 55 foods. \$ "Shopping" means "go shopping for dinner with guardians". \$ The number was described mother choose children's disliked food.

\section{Discussion}

The first, we checked changes in the same kindergarten over 10 years. Children's height, weight, food preferences and respect for food did not significantly change, and concern about food showed a slightly significant change (Figures 1-5). Height, weight and non-cognitive skills toward food (respect for food and concern about food) showed significant differences by age and sex (Figures 1, 2, 4, 5). During 3 to 5 years old children, there are large differences in physical and psychological characteristics according to age and sex. On the other hand, there were no significant differences in food preferences by age, sex and survey year (Figure 3). There were no changes in food preferences than physical and psychological by age and sex during 10 years.

We assessed non-cognitive skills summed up as 'concern about food' and 'respect for food'. Parental concern about adolescent weight was associated with lower intake of energy-dense snacks and less home availability of these food items (MacFarlane et al, 2010). In addition, our previous study suggested that the amount of vegetables in packed lunches may be related to mothers' concern for vegetables and children's preferences (Osera et al, 2017b). The present study showed the same tendency as MacFarlane's study and our previous study; the mother answered children's high and low of non-cognitive skills toward food were significantly related to their lifestyle and food habits in children of all ages (Table 4). Waking time, sleeping time, frequency of eating breakfast, talk about food, talk about taste and food preferences were significantly related to non-cognitive skills toward food but not to age and sex. Eating breakfast every day is associated with having a healthy body weight, likely due to a more even distribution of energy intake across meals throughout the day (Dubois et al, 2008). Omitting breakfast affected children's appetite ratings (Kral et al, 2011). In addition, compared with decreased sleep duration, increased sleep duration in school-age children resulted in lower reported food intake, lower fasting leptin levels and lower weight (Hart et al, 2013). Not only eating breakfast but also sleep duration is very important for children's food habits and correct food intake. Knowledge, attitude and behaviour (KAB) is an important theoretical model for health education, which asserts that behaviour change is affected by knowledge and attitude (Xu et al, 2010). According this theory, children and mothers important to take high concern about food and respect for food, after behaviour will be change and eating breakfast every day.

The study showed that children's consumption of soybean products was related to whether or not family members had conversations about food at meals and whether or not mothers told their children about Japanese foods (Osera et al, 2016b). The study showed that talking about food, talking about taste and food preferences were related to non-cognitive skills toward food. Conversation between mothers and children during meals may be important for the development of children's non-cognitive skills toward food. 
Helping to set the table, cooking and shopping for dinner with guardians were related to non-cognitive skills toward food and to children's age and sex. Utter et al. (2016) suggested that learning to cook and having the opportunity to cook may provide a unique means for adolescents to develop life skills and contribute positively to their families. We believe that this also applies to children. Because these three items are related to age, they can do any house work. The proportion of mothers who were identified as housewives significantly decreased over 10 years. In Japan, housewives do most of the cooking, washing and cleaning. These habits may have influenced the results of this study. Girls' scores were higher than boys' scores on these three items. In addition, these scores increased with increasing age (Table 4 and supplemental data, the data was not shown in the manuscript). Thus, the results suggested that high and low of non-cognitive skills toward food and housework related to cooking were significantly related to the child's sex.

Enjoying school lunch and number of food preferences were related to non-cognitive skills toward food and to age. The number of food preferences decreased with increasing age. Enjoying school lunch was significantly related to decreasing food preferences in our previous study (Osera et al, 2014). The kindergarten has school lunches, and kindergarten school lunch and nutrition education may be useful to decrease the number of food preferences. This opinion was supported by Lambert et al., who implied that teachers and school health professionals should improve the nutritional content of foods allowed in the classroom (Lambert et al, 2016). In the detail of the result, in food preferences, our result showed presence or absence of food preferences were significant differences by high and low of non-cognitive skills. There were no significant differences by age and sex. But the numbers of food preferences were significant differences by high and low of non-cognitive skills and age. In this study, food preference and the number of food preferences did not differ significantly by sex. Our previous study showed that the number of food preferences was significantly decreased during childhood and adolescence, as children grew up (Osera et al, 2016a). That study and other studies suggested that food preferences differed between boys and girls, and that these gender differences varied among elementary, middle and high school students (Osera et al, 2016a; Caine-Bish \& Scheule, 2009). Therefore, it could not still conclude but we consider that only during childhood were not significant differences by gender in food preferences. Nutrition education and school lunches are very useful to improve non-cognitive skills toward food in kindergarten children.

A limitation of the current study is that it was a cross-sectional study and therefore could not explain cause and effect. In the next study, we will try to clear using a retrospective study. It is important to take higher non-cognitive skills toward food during childhood and may influence future health. In the future, we will examine the cause and effect relations of children's non-cognitive skills toward food to nutrition education and school lunches. High non-cognitive skills toward food may be associated with to take good food habits in kindergarten children. In addition, since these data were of the secondary usage, it may be highly likely to have selection bias. Local data are needed because there are also differences in determinants of factors across cultures, places and ages.

\section{Conclusion}

Higher non-cognitive skills toward food during childhood are important because it may influence their food habits and lifestyle during childhood.

\section{Acknowledgments}

We thank all the children and teachers for their contributions to this study. We are also grateful to the teachers for their assistance.

\section{Author Contributions}

T.O., S.T., and N.K. developed the standardized protocol and structured questionnaire. M.K. conducted the focus group research in the kindergarten. T.O. drafted the manuscript. All authors critically revised the article for important intellectual content and approved the final manuscript.

\section{Conflicts of Interest}

This work was supported by JSPS KAKENHI Grant Number JP17K12925 for Tomoko Osera. The authors declare no conflict of interest. The founding sponsors had no role in the design of the study; in the collection, analyses, or interpretation of data; in the writing of the manuscript, and in the decision to publish the results.

\section{References}

Caine-Bish, N. L., \& Scheule, B. (2009). Gender differences in food preferences of school-aged children and adolescents. Journal of School Health, 79, 532-540. https://doi.org/10.1111/j.1746-1561.2009.00445.x 
Cashdan, E. (1998). Adaptiveness of food learning and food aversions in children. Social Science Information, 37, 613-632. https://doi.org/10.1177/053901898037004003.

Dubois, L., Girard, M., Kent, M.P., \& Farmer, A. (2008). Tatone-Tokuda, F. Breakfast skipping is associated with differences in meal patterns, macronutrient intakes and overweight among pre-school children. Public Health Nutrition, 12, 19-28. https://doi.org/10.1017/S1368980008001894

Duffy, V. D., \& Bartoshuk, L. M. (2000). Food acceptance and genetic variation in taste. Journal of American Diet Association, 100, 647-655. https://doi.org/10.1016/S0002-8223(00)00191-7

Hart, C. N., Carskadon, M. A., Considine, R. V., Fave, J. L., Lawton, J., Raynor, H. A., Jelalian, E., Owens, J., \& Wing, R. (2013). Changes in children's sleep duration on food intake, weight, and leptin. Pediatrics, 132, 1-8. https://doi.org/10.1542/peds.2013-1274

Heckman, J. J., Stixrud, J., \& Urzua, S. (2006). The effects of cognitive and noncognitive abilities on labor market outcomes and social behavior. Journal of Labor Economics, 24, 411-482. https://doi.org/10.3386/w12006

Imamura, E. Evaluation of infant physical development by Kaup index. Pediatric clinical pract. (1983). 36, 2107-2113.

Kral, T. V. E., Whiteford, L. M., Heo, M., \& Faith, M. S. (2011). Effect of eating breakfast compared with skipping breakfast on ratings of appetite and intake at subsequent meals in 8- to 10-y-old children. American Journal of Clinical Nutrition, 93, 284-291. https://doi.org/10.3945/ajcn.110.000505

Lambert, L. G., Chang, Y., Varner, J., \& Monroe, A. (2016). Allowing and using foods of low nutritional values in elementary school classrooms: the implications of teachers' beliefs. Journal of Nutrition Education Behavior, 48, 86-92. https://doi.org/10.1016/j.jneb.2015.08.022

Les, B., Duckworth, A. L., Heckman, J. J., \& Weel, B. T. (2008). The economics and psychology of personality traits. Journal of Human Resource, 43, 972-1059.

MacFarlane, A., Crawford, D., \& Worsley, A. (2010). Associations between parental concern for adolescent weight and the home food environment and dietary intake. Journal of Nutrition Education Behavior, 42, 152-160. https://doi.org/10.1016/j.jneb.2008.11.004

Osera, T., Tsutie, S., Kobyashi, M., \& Kurihara, N. (2014). A retrospective study on the relationship of changes in likes/dislikes with food habits in 4- and 6- year-old children. European Journal of Nutrition \& Food Safety, 4, 604-613. https://doi.org/10.9734/EJNFS/2014/10604x

Osera, T., Tsutie, S., Kobayashi, M., Sato, T., \& Kurihara, N. (2016a). Associations between children's food preferences and food habits towards healthy eating in Japanese children. Jouranal of Child and Adolescent Behavior, 4, 1000292. https://doi.org/10.4172/2375-4494.1000292

Osera, T., Tsutie, S., Kobayashi, M., \& Kurihara, N. (2016b). Using soybean products in school lunch for health education may improve children's attitude and guardians' knowledge in kindergarten. Jouranal of Child and Adolescent Behavior, 4, 1000310. http://doi.org/10.4172/2375-4494.1000310

Osera, T., Awai, M., Tsutie, S., Kobayashi, M., \& Kurihara, N. (2017a). A retrospective study on changes in food preferences of Japanese high school students from childhood to the present day. Journal of Food Research, 6, 150-158. https://doi.org/10.5539/jfr.v6n4p150

Osera, T., Tsutie, S., Kobayashi, M., \& Kurihara, N. (2017b). Evaluation of children's lunch box contents by photograph and their relationship with mother's concern. Journal of Food Research, 6, 78-86. https://doi.org/10.5539/jfr.v6n1p78

Scaglioni, S., \& Salvioni, M. (2008). Galimberti, C. Influence of parental attitudes in the development of children eating behavior. British Journal of Nutrition, 99, S22-S25.

https://doi.org/10.1017/S0007114508892471

Schweinhart, L. J. (2005). The high/scope perry preschool study through age 40. Summary, conclusions, and frequently asked questions. High/Scope Education Research Foundation. http://www.peelearlyyears.com/pdf (accessed on 238 2017)

St-onge, M., Keller, K. L., \& Heymsfield, S. B. (2003). Changes in childhood food consumption patterns: a cause for concern in light of increasing body weights. American Journal of Clinical Nutrition, 78, 1068-1073. 
Utter, J., Denny, S., Lucassen, M., \& Dyson, B. (2016). Adolescent cooking abilities and behaviors: associations with nutrition and emotional well-being. Journal of Nutrition Education Behavior, 48, 35-41. http://doi.org/10.1016/j.jneb.2015.08.016

Xu, W., Sun, G., Lin, Z., Chen, M., Yang, B., Chen, H., \& Cao, K. (2010). Knowledge, attitude, and behavior in paients with atrial fibrillation undergoing radiofrequency catheter ablation. Journal of Intervention Cardiac Electrophysiology, 28, 199-207. https://doi.org/10.1007/s10840-010-9496-2

\section{Appendix A}

Appendix A. Relationship between noncognitive skills toward food, age and sex

\begin{tabular}{|c|c|c|c|c|c|c|c|c|c|c|c|c|c|c|c|c|c|c|c|}
\hline & \multicolumn{8}{|l|}{ Boy } & \multicolumn{11}{|l|}{ Girl } \\
\hline & \multicolumn{4}{|l|}{ High } & \multicolumn{4}{|c|}{ Low } & \multicolumn{4}{|l|}{ High } & \multicolumn{4}{|c|}{ Low } & \multicolumn{3}{|l|}{ P value } \\
\hline & & & & $\mathrm{N}$ & & & & $\mathrm{N}$ & & & & $\mathrm{N}$ & & & & $\mathrm{N}$ & skill & sex & age* \\
\hline Waking time $^{+}$ & 3.3 & \pm & 0.7 & 318 & 3.3 & \pm & 0.7 & 300 & 3.3 & \pm & 0.6 & 444 & 3.1 & \pm & 0.6 & 298 & $<0.001$ & N.S. & N.S. \\
\hline Sleeping time ${ }^{+}$ & 2.5 & \pm & 0.8 & 316 & 2.3 & \pm & 0.7 & 296 & 2.5 & \pm & 0.7 & 441 & 2.3 & \pm & 0.8 & 292 & $<0.001$ & N.S. & N.S. \\
\hline Help set the table $e^{++}$ & 4.0 & \pm & 0.8 & 129 & 3.5 & \pm & 1.1 & 145 & 4.1 & \pm & 0.8 & 200 & 3.8 & \pm & 0.9 & 145 & $<0.001$ & $<0.01$ & $<0.001$ \\
\hline Cooking & 3.6 & \pm & 1.1 & 386 & 3.1 & \pm & 1.1 & 348 & 3.8 & \pm & 0.9 & 523 & 3.6 & \pm & 1.0 & 344 & $<0.001$ & $<0.001$ & $<0.001$ \\
\hline Shopping $\$$ & 4.2 & \pm & 0.9 & 312 & 4.1 & \pm & 1.0 & 267 & 4.5 & \pm & 0.6 & 394 & 4.3 & \pm & 0.9 & 255 & $<0.001$ & $<0.001$ & $<0.001$ \\
\hline $\begin{array}{l}\text { Enjoying } \\
\text { school lunch }\end{array}$ & 4.5 & \pm & 0.8 & 318 & 3.9 & \pm & 0.9 & 298 & 4.6 & \pm & 0.6 & 439 & 3.9 & \pm & 0.9 & 298 & $<0.001$ & N.S. & $<0.001$ \\
\hline Eat breakfast & 4.0 & \pm & 0.1 & 386 & 4.0 & \pm & 0.2 & 348 & 4.0 & \pm & 0.1 & 522 & 3.9 & \pm & 0.3 & 344 & $<0.001$ & N.S. & N.S. \\
\hline Talk about food & 4.2 & \pm & 0.7 & 317 & 3.8 & \pm & 0.8 & 300 & 4.2 & \pm & 0.6 & 444 & 3.7 & \pm & 0.8 & 297 & $<0.001$ & N.S. & N.S. \\
\hline Talk about taste & 4.3 & \pm & 0.7 & 197 & 3.9 & \pm & 0.8 & 185 & 4.3 & \pm & 0.7 & 283 & 3.9 & \pm & 0.7 & 191 & $<0.001$ & N.S. & N.S. \\
\hline Food preference ${ }^{+++}$ & 0.8 & \pm & 0.4 & 378 & 0.9 & \pm & 0.3 & 337 & 0.8 & \pm & 0.4 & 514 & 0.9 & \pm & 0.3 & 337 & $<0.001$ & N.S. & N.S. \\
\hline $\begin{array}{l}\text { Number of food } \\
\text { preferences }^{+++\$ \$}\end{array}$ & 5.6 & \pm & 5.7 & 145 & 9.1 & \pm & 8.3 & 164 & 4.4 & \pm & 3.7 & 225 & 8.5 & \pm & 6.7 & 173 & $<0.001$ & N.S. & $<0.001$ \\
\hline
\end{tabular}

Note. The relationship between non-cognitive skills toward food, age and sex were assessed using three way ANOVA; $* \mathrm{p}<0.05, * * \mathrm{p}<0.01$, *** $\mathrm{p}<0.001$; The maximum total score for concern about food and respect for food was 10, the minimum was 1 and the mean and standard deviation were 7.6 \pm 1.6 . Based on this, we devided into two groups. According to this procedure compared between high and low of two non-cognitive skills toward food, respect for food and concern about food. The data showed including all age children.* Mean of each age data was not shown. + Up to 4 point scale. Good habits indicate 4 point. ++ Up to 5 point scale. Good habits indicate 5 point. +++ 'Presence' means that students dislike more than one foods, 'Absence' means that students disliked no food. 1 was 'presence' and 0 was 'absence'. ++++ The foods student disliked, which were chosen themselves from a list of 55 foods. \$ "Shopping" means "go shopping for dinner with guardians". \$ \$ The number was described mother choose children's disliked food.

\section{Copyrights}

Copyright for this article is retained by the author(s), with first publication rights granted to the journal.

This is an open-access article distributed under the terms and conditions of the Creative Commons Attribution license (http://creativecommons.org/licenses/by/4.0/). 